\title{
Use of Waste Plastics in Coke Oven: A Review
}

\author{
Seiji Nomura
}

Published online: 8 January 2015

(C) The Minerals, Metals \& Materials Society (TMS) 2015

\begin{abstract}
To help in building a recycling-oriented sustainable society, Nippon Steel \& Sumitomo Metal Corporation developed a waste plastic-recycling process using coke oven and put it into commercial operation in 2000. Now roughly 200,000 tons per year of waste plastics are processed in coke oven in Japan. In this process, the waste plastics collected from households are agglomerated to the sizes ranging from 20 to $30 \mathrm{~mm}$ in diameter and charged into coke ovens with coal at the blending ratio of about 1 mass $\%$. Waste plastics are thermally decomposed into approximately 20 mass $\%$ coke, 40 mass $\%$ hydrocarbon oil (tar and light oil) and 40 mass $\%$ coke oven gas, which are utilized as iron ore-reducing agents in blast furnaces, raw materials for the chemical industry, and a fuel for power plants, respectively. Moreover, 92 mass $\%$ of the chlorine in waste plastics is released and absorbed by the ammonia liquor spray for cooling hot coke oven gas and converted to ammonium chloride. The waste plastic-recycling process using coke ovens is superior in that a large amount of waste plastics can be treated, useful materials can be recovered using the existing facilities, coke quality can be kept the same and the chlorine released from waste plastics can be fixed in the existing ammonia liquor spray system.
\end{abstract}

Keywords Waste plastic recycling - Coke Coal . Chlorine $\cdot$ Carbonization

S. Nomura $(\bowtie)$

Ironmaking Research Laboratory, Process Research

Laboratories, Nippon Steel \& Sumitomo Metal Corporation,

20-1, Shintomi, Futtsu, Chiba 293-8511, Japan

e-mail: nomura.e9c.seiji@jp.nssmc.com

\section{Introduction}

During the 1990s, the amount of industrial and domestic plastic waste in Japan increased steadily from 6 to 10 million ton as shown in Fig. 1 [1]. Each year, households in Japan discard about 5 million tons of waste. In Japan, where landfill area is limited, the recent increase in disposal of materials such as waste plastics was expected to become a serious social problem. However, in 2000, landfilling and incineration accounted for more than 50 mass $\%$ of waste plastic disposal, and the waste plastic utilization ratio was only less than 50 mass $\%$ as shown in Fig. 2 [2]. Therefore, an effective measure to increase the waste plastic utilization ratio was needed to solve the problem of shortages in landfills and incineration sites.

Therefore, in order to promote the conversion of the discarded containers and packaging, which accounts for 70 mass \% of the domestic waste plastic as shown in Fig. 3 [2], into a "resource", the Container Package Recycling Law was officially announced in 1995 and came into force in April 2000. Since then, the effective uses of plastic waste (mechanical recycle, feedstock recycle and energy recovery) have been increasing steadily as shown in Fig. 2.

Under these conditions, Japanese steel industry has made various efforts to develop waste plastic-recycling processes using its ironmaking process. There are two major feedstock-recycling processes applied in commercial scale operations; one is the blast furnace feedstock recycling and the other is the coke oven chemical feedstock recycling.

In the former process, waste plastics are used as a substitute reducing agent for coke and pulverized coal in a blast furnace to produce pig iron [3-5]. Pig iron is produced in a blast furnace by melting and reducing iron ore by use of coke. Waste plastics composed of carbon and 
Fig. 1 Changes in resin production, domestic resin product consumption, industrial plastic waste [1] plastic waste and domestic

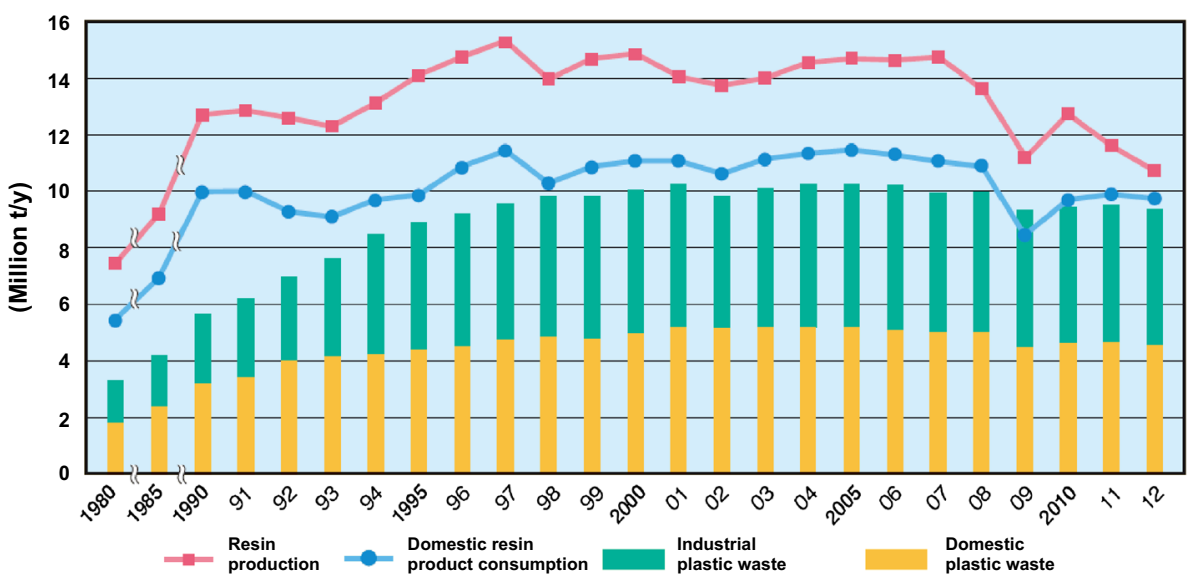

Fig. 2 Changes in utilized plastic waste by amount and rate [2]

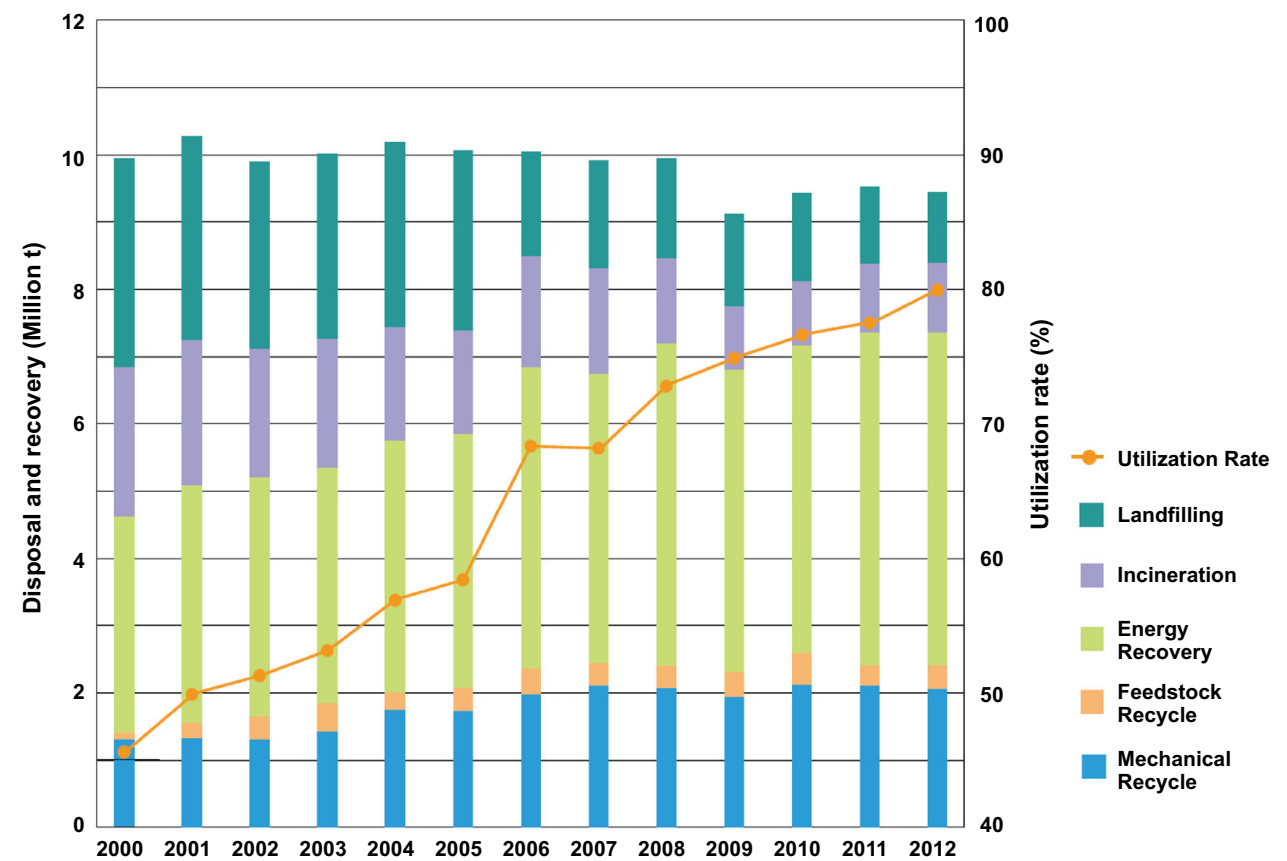

hydrogen act as a reducing agent in the blast furnace process to remove oxygen from iron oxide, one of the main constituents of iron ore. In this process, collected plastic waste is dechlorinated and finely pulverized, and then injected into the blast furnace through tuyeres along with pulverized coal as a reducing agent. The facilities constructed in 2007 at JFE Keihin consist of a melting/mixing process, dechlorination process and crushing process for waste plastics, and produce 8,000 t/y of pulverized plastics with mean diameters ranging from 0.2 to $0.4 \mathrm{~mm}$ [4]. Finer pulverization is advantageous from the viewpoint of combustibility. It is necessary to crush a single plastic or mixed plastics in cool atmosphere, because heat generated by pulverization causes the plastic to soften and melt. In the case of waste plastics composed of different plastics, when they are melted and mixed in a fine mixture and then cooled to room temperature, stresses are generated at the interfaces between the heterogeneous plastics, which result in cracks in the melting material. Then, waste plastics can be pulverized using a conventional pulverizer.

In the latter process, waste plastics are used to produce coke, coke oven gas (COG) and hydrocarbon oil in a coke oven $[6,7]$. Coke is produced in a coke oven by carbonizing (heat treating without oxygen at high temperature) coal. Waste plastics composed of carbon and hydrogen are converted to coke, COG and hydrocarbon oil like coal in the coking chamber. In this process, collected plastic waste is agglomerated and charged into the coke oven with coal. Nippon Steel \& Sumitomo Metal Corporation (NSSMC) has developed a commercial-scale waste plastic-recycling process using coke ovens, which can treat a large amount of waste plastic, and these commercial-scale waste plastic- 


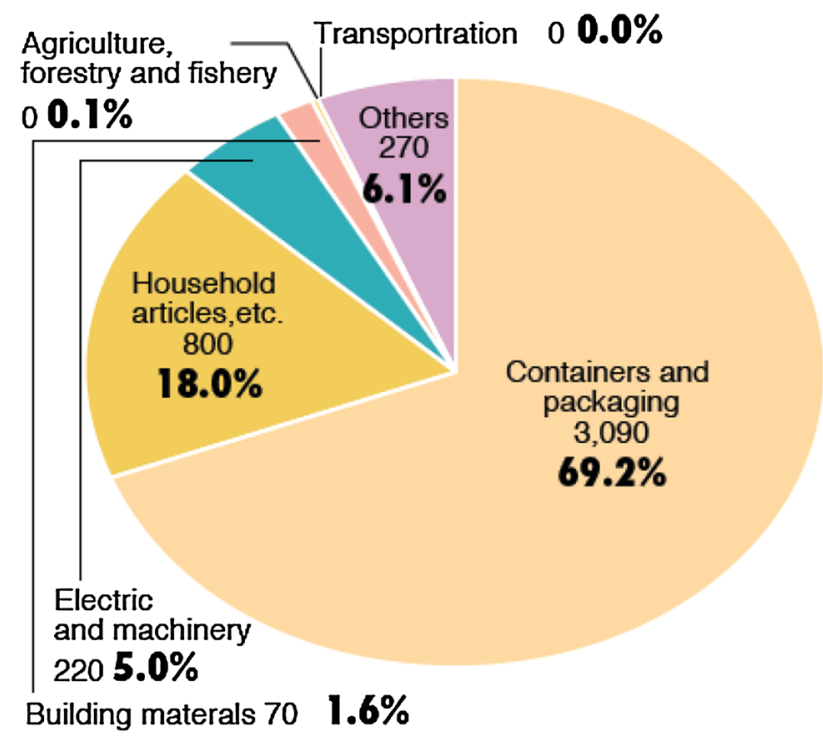

Fig. 3 Breakdown of domestic waste by field (4,460 kt) [2]

recycling plants have been operating successfully. In this report, the outline of the development of waste plasticrecycling process using coke ovens is reviewed.

\section{Outline of Cokemaking Process}

Figures 4 and 5 [8] show the outline of the cokemaking process. The coal is charged in a coking chamber through charging holes and is heated to about $1,100{ }^{\circ} \mathrm{C}$ in an oxygen-free condition and pyrolyzed. Heat is supplied from the combustion flues which are separated from the coking chamber by silica brick walls, and coal is transformed to coke through a stage of softening and cohesive zone as shown in Fig. 6 [7]. High-temperature COG leaving the coking chamber, which includes tar component, ammonia, water and so forth in gas phase, is flushed with the ammonia liquor at the gas exit part of the coking chamber (which is called the 'gooseneck'), and cooled to about $80{ }^{\circ} \mathrm{C}$. In addition, COG is cooled to about $35^{\circ} \mathrm{C}$ with a primary gas cooler. Then, condensed liquid is

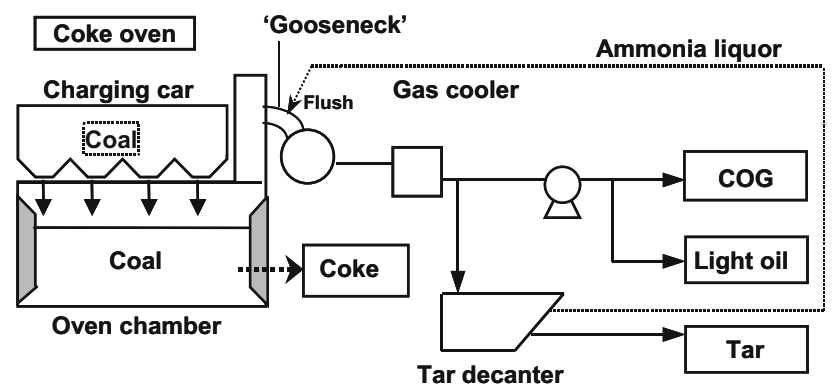

Fig. 4 Outline of cokemaking process

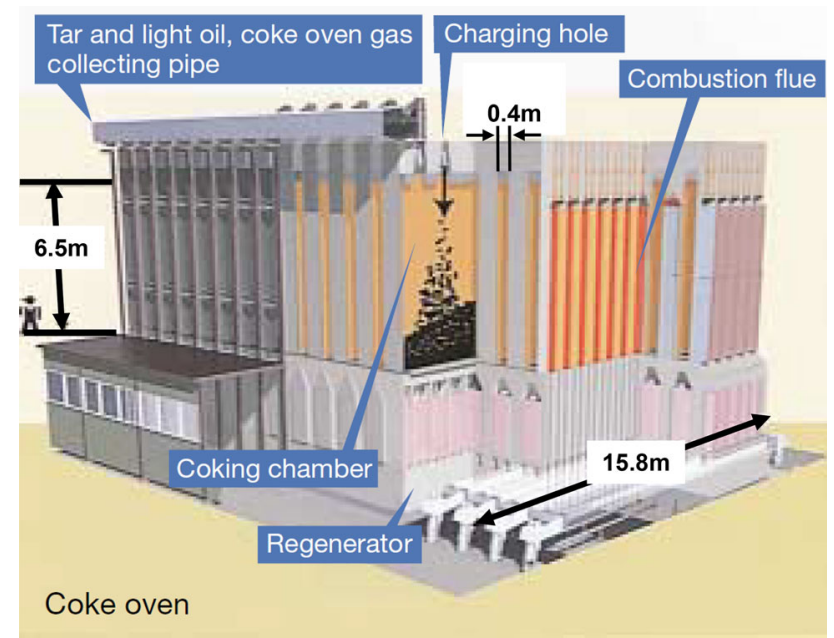

Fig. 5 Schematic view of coke oven [8]

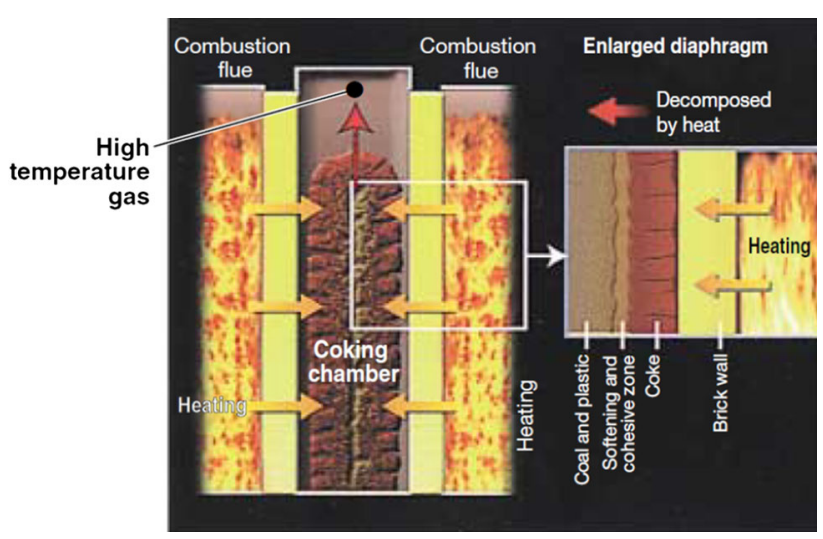

Fig. 6 Schematic view of inside of coke oven [8]

separated to tar and ammonia liquor at a tar decanter. Light oil is recovered from COG. Coke is used in a blast furnace to reduce iron ores and to supply heat, while light oil and tar are used as chemical raw materials, COG is used as fuel gas, and ammonia liquor is circulated for flushing.

It is thought that the cokemaking process is suitable for a waste plastic-recycling process thanks to the following three factors. First, there is a possibility that waste plastics do not burn but decompose to produce chemically useful materials in a coking chamber. Secondly, the cokemaking process is generally equipped with the facilities to recover the decomposition product of waste plastics, which of course makes recovery easier. Thirdly, hydrogen chloride, $\mathrm{HCl}$, which is considered to generate during the carbonization of waste plastics containing PVC (polyvinylchloride) can be trapped by ammonia liquor which is normally used for cooling hot COG.

There are three fundamental and important questions to be answered in developing the waste plastic-recycling process using coke ovens. The first question refers to what 
products are obtained when waste plastics are carbonized and decomposed with coal in a coking chamber. The second is whether the co-carbonization of coal with waste plastics affects the quality of coke, which is important for stable blast furnace operations. The third is the behaviour of chlorine during co-carbonization of coal and waste plastics containing chloride compounds such as PVC.

\section{Investigation on the Waste Plastic-Recycling Process Using Coke Ovens}

Product Yield of Waste Plastics

Figure 7 shows the weight loss of various types of plastics and a typical hard coking coal measured as a function of temperature using TGA in nitrogen atmosphere at a constant heating rate of $3^{\circ} \mathrm{min}^{-1}$ [9]. The sample weight is about $10 \mathrm{mg}$, and its size is less than $150 \mu \mathrm{m}$. While polyethylene (PE), polypropylene (PP) and polystyrene (PS) are decomposed almost completely, about 10 mass\% of polyethylene terephthalate (PET) and polyvinylchloride (PVC) remain as undecomposed residues in TGA experiment.

The product yield of various plastics was also measured using a laboratory-scale coke oven shown in Fig. 8 [6]. In this experiment, $100 \mathrm{~g}$ of plastic samples were carbonized, and the amounts of decomposition products of plastics [solid residue (coke), liquid (tar and light oil) and gas (COG)] were measured. As shown in Fig. 9, the amount of decomposition product varies according to the plastic types. The yield of coke (solid residue) in the laboratory scale test is higher than that obtained in the TGA experiment. There have been some studies on the composition of tars produced from coal and plastic blends [10, 11].

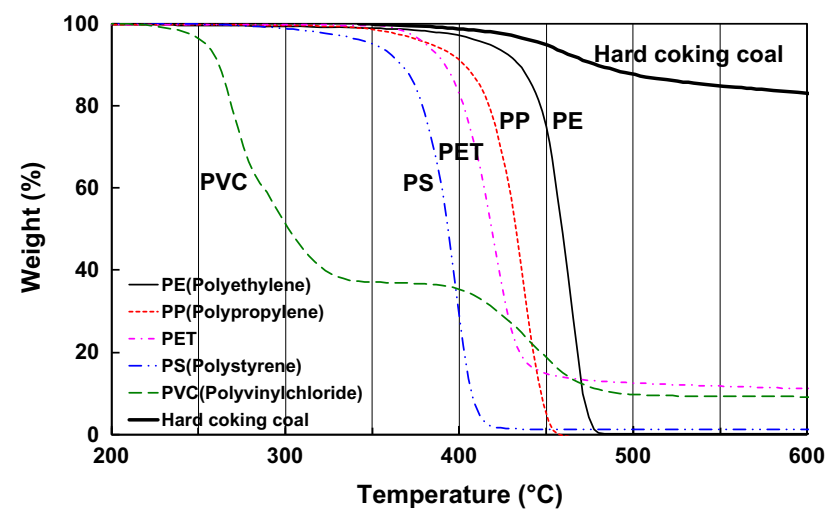

Fig. 7 Thermogravimetric analysis of various kinds of plastics and a coal

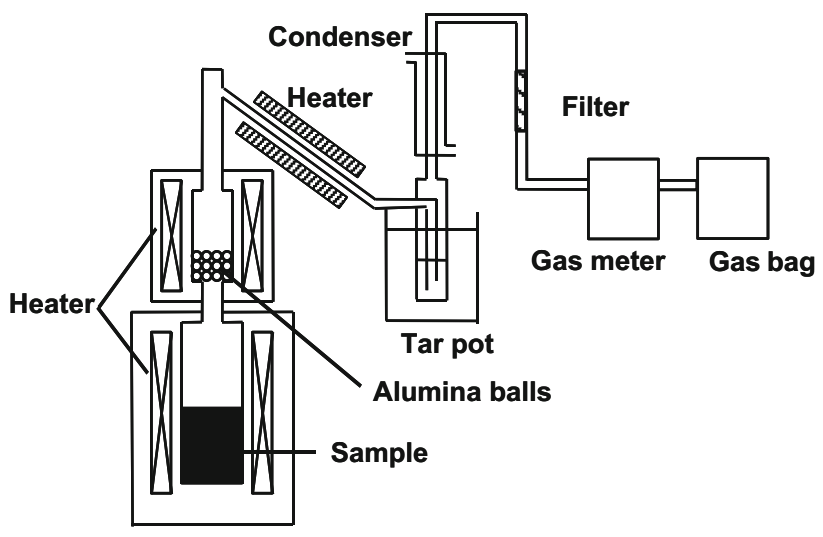

Lab.- scale coke oven

Fig. 8 Experimental apparatus

Finally, the conversion rates of waste plastics into various products were investigated in a commercial-scale coke oven [6, 7]. Tables 1 and 2 show the ultimate analysis and ash contents of waste plastics and the component of waste plastics, respectively. The product yields were approx. 20 mass $\%$ for coke, 40 mass $\%$ for tar and light oil and 40 mass\% for gases (Fig. 9). It was proved that useful products such as coke, tar and light oil, and high calorie gas can be obtained by carbonizing waste plastics with coal in a commercial scale coking chamber.

Influence of Plastic Addition on Coke Quality

The subject of plastic addition effect on coke quality is divided into three items. The first is the effect of the added plastic type on the coke quality, because household waste plastics include various types of plastics that vary greatly in composition. The second is the effect of the added plastic size on coke quality. The third is the effect of the addition ratio of plastic to coal on coke quality.

As for the effect of plastic type, there have been many studies on the influence of plastic addition on coal-caking property and coke quality [12-25]. It was revealed that thermal decomposition products of plastics interacted with bituminous coal during carbonization in a coke oven. Nomura et al. [9] showed that the effect of plastic addition on coal-caking property varied with the types of plastics. As shown in Figs. 10 and 11, the addition of PE and PVC had only a small effect on coal-caking property and coke strength $\left(\mathrm{DI}_{15}^{150}\right)$, and in some cases, $\mathrm{PE}$ addition increased coke strength. On the other hand, the addition of PS and PET inhibited coal expansion and fusion, and deteriorated the coke strength. Here $\mathrm{DI}_{15}^{150}$ is the JIS drum index of coke (percentage of coke mass retained on a sieve with $15-\mathrm{mm}$ apertures to the original mass of the coke sample after 150 revolutions in the JIS drum tester) (JIS K2151, [26]). These 
Fig. 9 Decomposition product yield of plastics in a laboratoryscale test and a commercialscale test

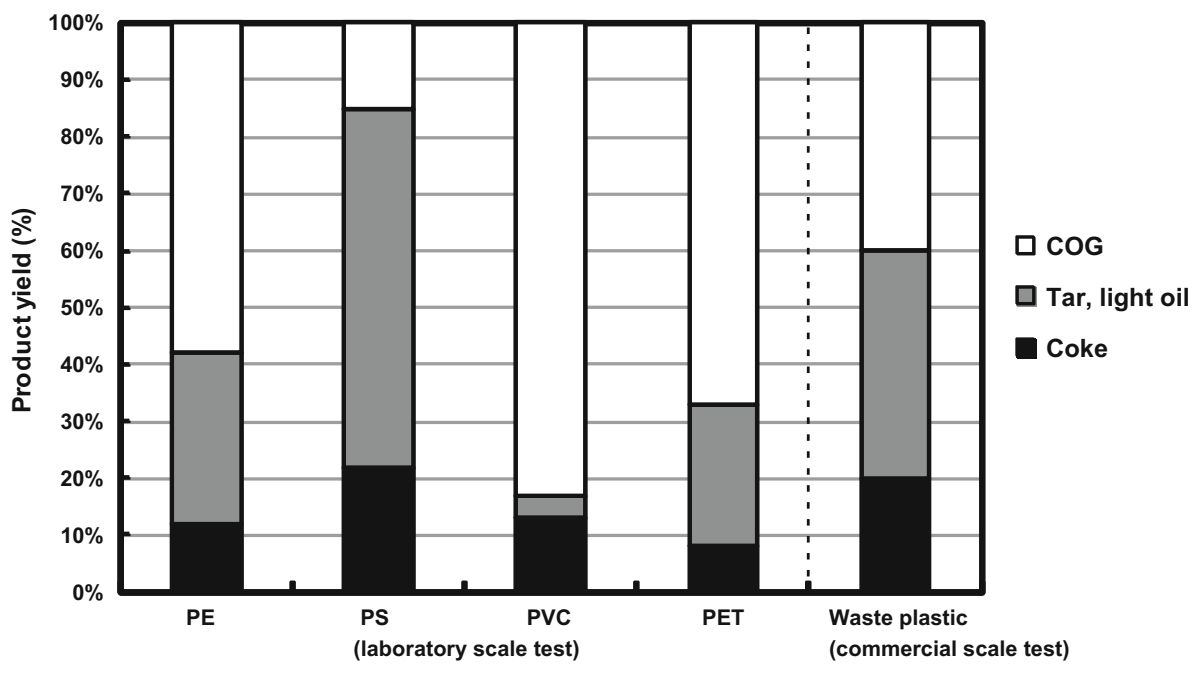

Table 1 Ultimate analysis and ash content of waste plastics

\begin{tabular}{lllll}
\hline \multicolumn{2}{l}{ Ultimate analysis (mass\%, dry) } & & \multirow{2}{*}{ Ash (mass\%) } \\
\hline C & H & N & S & \\
\hline 72.6 & 9.2 & 0.3 & 0.04 & 5.0 \\
\hline
\end{tabular}

differences were discussed from the viewpoint of the interaction between thermal decomposition products of plastics and hydrogen in coal. It was suggested that the radicals formed as a result of PS or PET thermal decomposition abstracted hydrogen from the coal, which resulted in the decrease in coal-caking property.

As for the effect of plastic size, there have been few studies so far. Nomura et al. [22] investigated the effect of the added plastic size on coke quality and drew an important conclusion that the coke strength $\left(\mathrm{DI}_{15}^{150}\right)$ reached a minimum at a certain plastic size in the case of a certain plastic addition rate. For example, in the case of a plastic addition rate of 2 mass $\%$, the coke strength $\left(\mathrm{DI}_{15}^{150}\right)$ reached a minimum at the particle size of $10 \mathrm{~mm}$ for polyethylene (PE) and $3 \mathrm{~mm}$ for polystyrene (PS). These results indicate that large or small plastic particles are favourable in order to add waste plastics to blended coals for cokemaking without affecting coke strength $\left(\mathrm{DI}_{15}^{150}\right)$. The reason why coke strength increases with increasing plastic size is because amount of the weak coke structure formed on the interface between plastic and coal decreases. The total

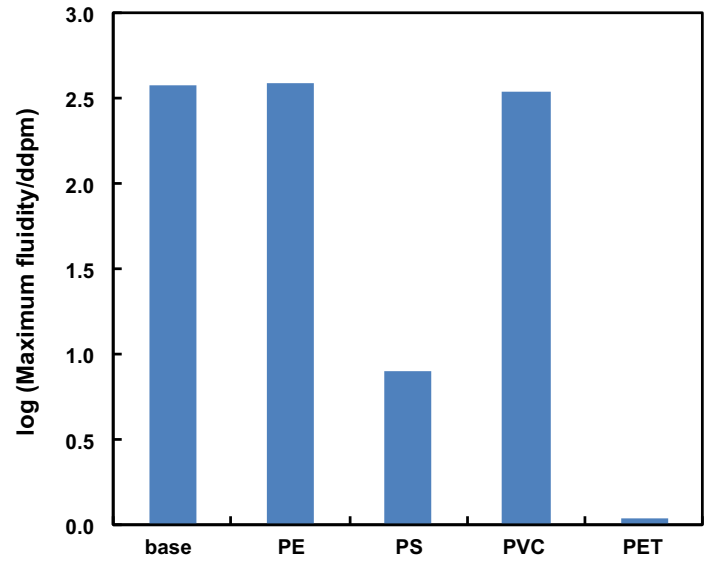

Fig. 10 Effect of 5 mass\% addition of various plastics to a typical hard coking coal (VM 23.8 mass\%) on maximum fluidity

surface area of the added plastic particles, $A\left(\mathrm{~cm}^{2}\right)$, is expressed as follows:

$W=N \times \rho \times\left(4 \pi r^{3} / 3\right)$

$\mathrm{SA}=4 \pi r^{2} / \rho /\left(4 \pi r^{3} / 3\right)=3 /(\rho r)$

$A=N \times 4 \pi r^{2}=3 W /(\rho r)=W \times \mathrm{SA}$

where $W$ is the mass of added plastic ( $\mathrm{g}), N$ is the number of the added plastic particles, $\rho$ is the plastic density

Table 2 Component of waste plastics

\begin{tabular}{llllll}
\hline Component $(\mathrm{mass} \%)$ & & & & \\
\hline Polyethylene (PE) & Polypropylene (PP) & Polystyrene (PS) & Polyvinylchloride (PVC) & PET & Others \\
\hline 21.4 & 13.7 & 24.8 & 5.2 & 15.5 & 19.4 \\
\hline
\end{tabular}




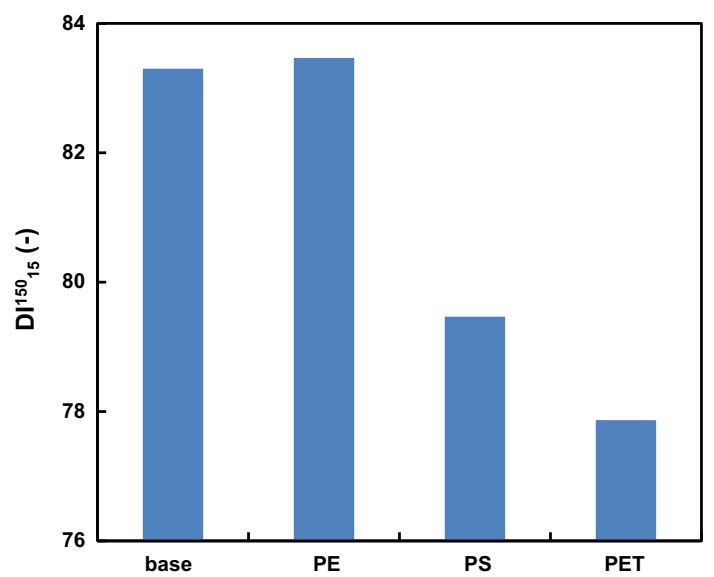

Fig. 11 Effect of 2 mass\% addition of various plastics on coke strength $\mathrm{DI}_{15}^{150}$

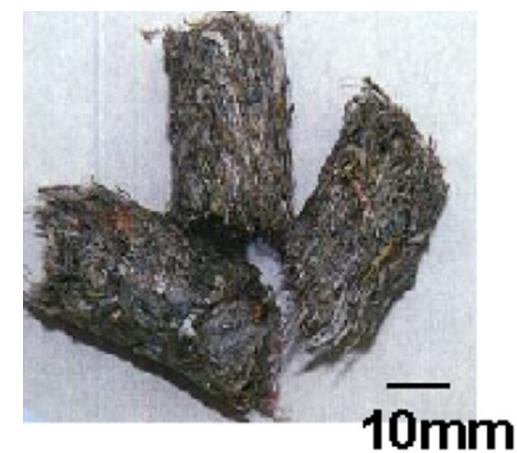

Fig. 12 Agglomerated waste plastics

$\left(\mathrm{g} / \mathrm{cm}^{3}\right), \mathrm{r}$ is the mean radius of the plastic $(\mathrm{cm})$ and SA $\left(\mathrm{cm}^{2} / \mathrm{g}\right)$ is the specific surface area of the added plastic particles. As shown here, the total surface area is inversely proportional to the plastic radius and density. Therefore, when the mass of the added plastic is the same, increases in the plastic size and density lead to a decrease in the total surface of the added plastic particles, which decreases weak coke structure and hence increases coke strength.

Based on this fundamental study, and considering the ease of handling plastics, NSSMC determined to use agglomerated waste plastics with a range of $20-30 \mathrm{~mm}$ in diameter as shown in Fig. 12 in a commercial-scale waste plastics-recycling process using coke ovens.

The effect of waste plastic addition on coke strength was investigated in a commercial cokemaking plant by adding two types of waste plastics at the blending ratios of 0.9-2.0 mass\%. One was "light" waste plastic having the apparent density of $0.52-0.56 \mathrm{~g} / \mathrm{cm}^{3}$, and the other was "heavy" plastic having the apparent density of $0.86 \mathrm{~g} / \mathrm{cm}^{3}$. In the case of the light waste plastic, as shown in Fig. 13, 1 mass\% addition did not affect $\mathrm{DI}_{15}^{150}$; however, 1.5 mass\%

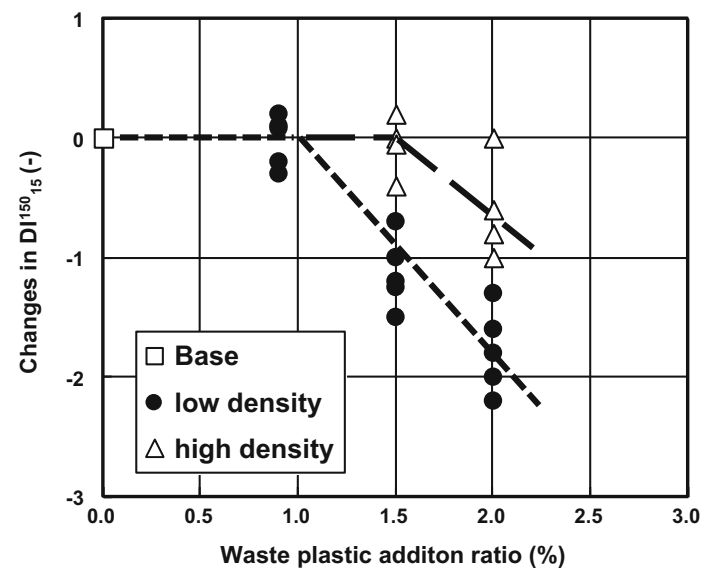

Fig. 13 Relationship between waste plastic addition ratio and changes in $\mathrm{DI}_{15}^{150}$

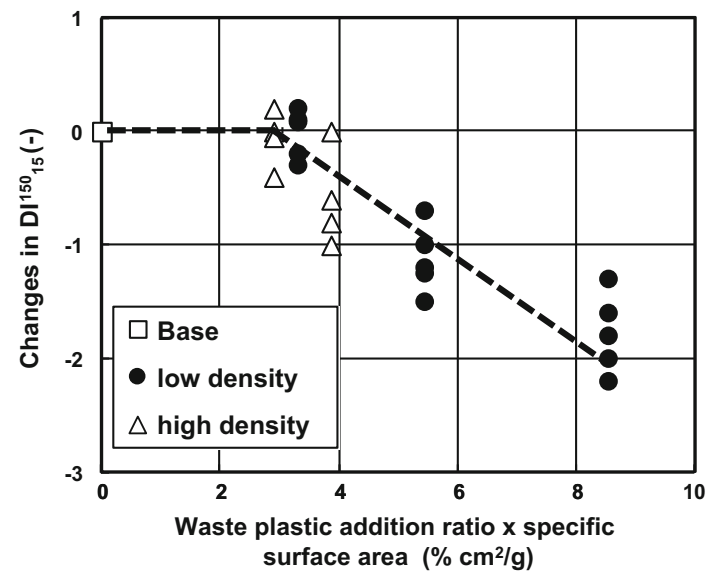

Fig. 14 Relationship between waste plastic addition ratio multiplied by specific surface area and changes in $\mathrm{DI}_{15}^{150}$

addition deteriorated $\mathrm{DI}_{15}^{150}$. On the other hand, in the case of the heavy waste plastic, 1.5 mass $\%$ addition did not affect $\mathrm{DI}_{15}^{150}$; however, 2.0 mass\% addition deteriorated $\mathrm{DI}_{15}^{150}$. Therefore, by using denser plastic agglomerate, more waste plastics could be added to coal without affecting the coke strength. It has been revealed that PS and PET deteriorate the caking ability of coal [9]; however, as long as the addition rate of waste plastics is within limited range (below 2 mass\%), the effect of plastic addition on coke quality can be neglected. Moreover, as shown in Fig. 14, the effect of different-density waste plastics on coke strength was expressed by a single line by using the total surface area of the added plastic particles calculated by the multiplication of the waste plastic addition ratio and specific surface area of the plastic particle. This agrees well with the theory that coke strength is determined by the total surface area of the added plastic particles which is calculated by the above equation. 


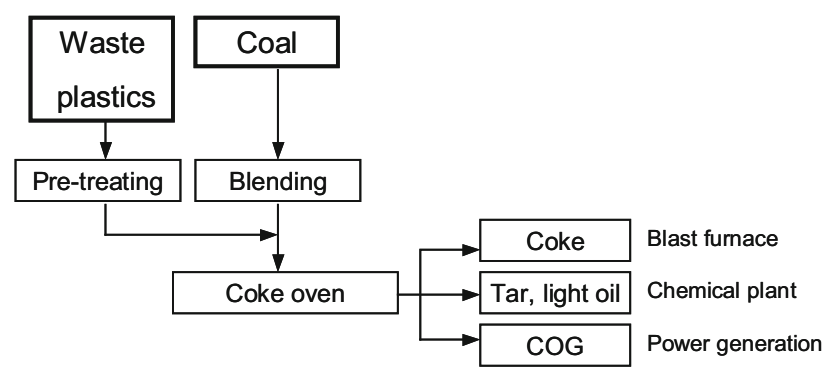

Fig. 15 Outline of waste plastic-recycling process using coke ovens

Behaviour of Chlorine in Waste Plastics

Household waste plastics include organic chloride compounds such as polyvinyl chloride (PVC), polyvinylidene chloride and other chlorinated plastics. Since the chlorine in waste plastic is likely to become hydrogen chloride as a result of thermal decomposition, which can lead to the corrosion of the equipment, dechlorination treatment is necessary. Therefore, to investigate the behaviour of chlorine in waste plastics as well as in coal during carbonization [27-30] is an important subject.

In order to tackle this problem, commercial-scale coke oven tests were carried out by adding 1 or 2 mass $\%$ of waste plastics containing 2.5-3.2 mass\% chlorine to blend coals containing $450 \mathrm{ppm}$ chlorine [31]. The result was that the addition of chlorine from waste plastics to coal hardly affected the chlorine content in coke and COG. Most of the released chlorine was absorbed by the ammonia liquor spray for cooling hot $\mathrm{COG}$ and converted to ammonium chloride by a chemical reaction $\left(\mathrm{HCl}+\mathrm{NH}_{3}=\mathrm{NH}_{4} \mathrm{Cl}\right)$ (Fig. 4).

The chlorine in waste plastics was distributed to the coke, the ammonia liquor and the COG by (in mass\%) 7 , 92 and $1 \%$, respectively, while the chlorine in coal was distributed by 43,56 and 1 mass $\%$, respectively. The reason why chlorine residue ratio in coke derived from waste plastics is much lower than that derived from coal is due to the difference in the mode of occurrence of chlorine in waste plastics (mainly PVC) and coal. The decomposition of PVC added to coal is much faster than the release of chlorine from coal during carbonization [32].

\section{Waste Plastic-Recycling Process Using Coke Ovens}

Figure 15 shows the flow of the waste plastic-recycling process using coke ovens. After waste plastics are pre-treated, they are mixed with coal blends, charged into coke ovens and carbonized. Waste plastics are carbonized at high temperature, and decomposed into coke, tar, light oil and gas.

The waste plastics of the non-industrial waste types are collected as forms of bags, films, foamed bodies and powders. Therefore, it is necessary to pre-treat the collected waste plastics and change their shape and size to make them suitable for charging into coking chambers. Figure 16 shows the waste plastics pre-treating flow [6-8]. First, metals are removed from the waste plastics using magnetic sorting. Then, they are coarsely crushed by crusher and extraneous material is removed using a separator. After fine crushing to about $10 \mathrm{~mm}$, their volume is reduced using an agglomerator (screw kneader) at $120{ }^{\circ} \mathrm{C}$. They are cut to a diameter ranging from about 20-30 mm, air-cooled on a conveyor belt, mixed in advance with coal and charged into the coking chambers.

The products of coke oven are used for re-commercialization as shown in Fig. 17 [7]. The hydrocarbon oil (tar and light oil) is utilized as chemical feedstock for container and packaging resins, electronic materials and paints, the coke as iron ore-reducing agent, and the COG utilized at the steelworks power plant.
Fig. 16 Waste plastics pretreating flow [6-8]

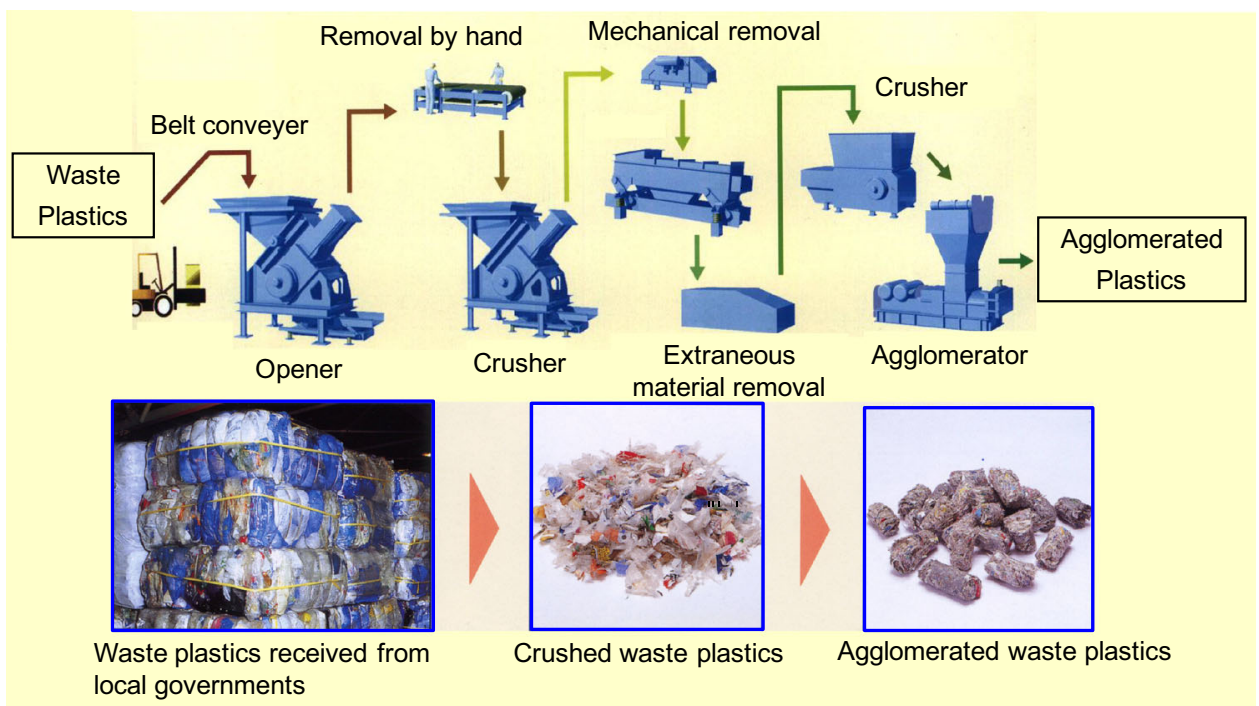



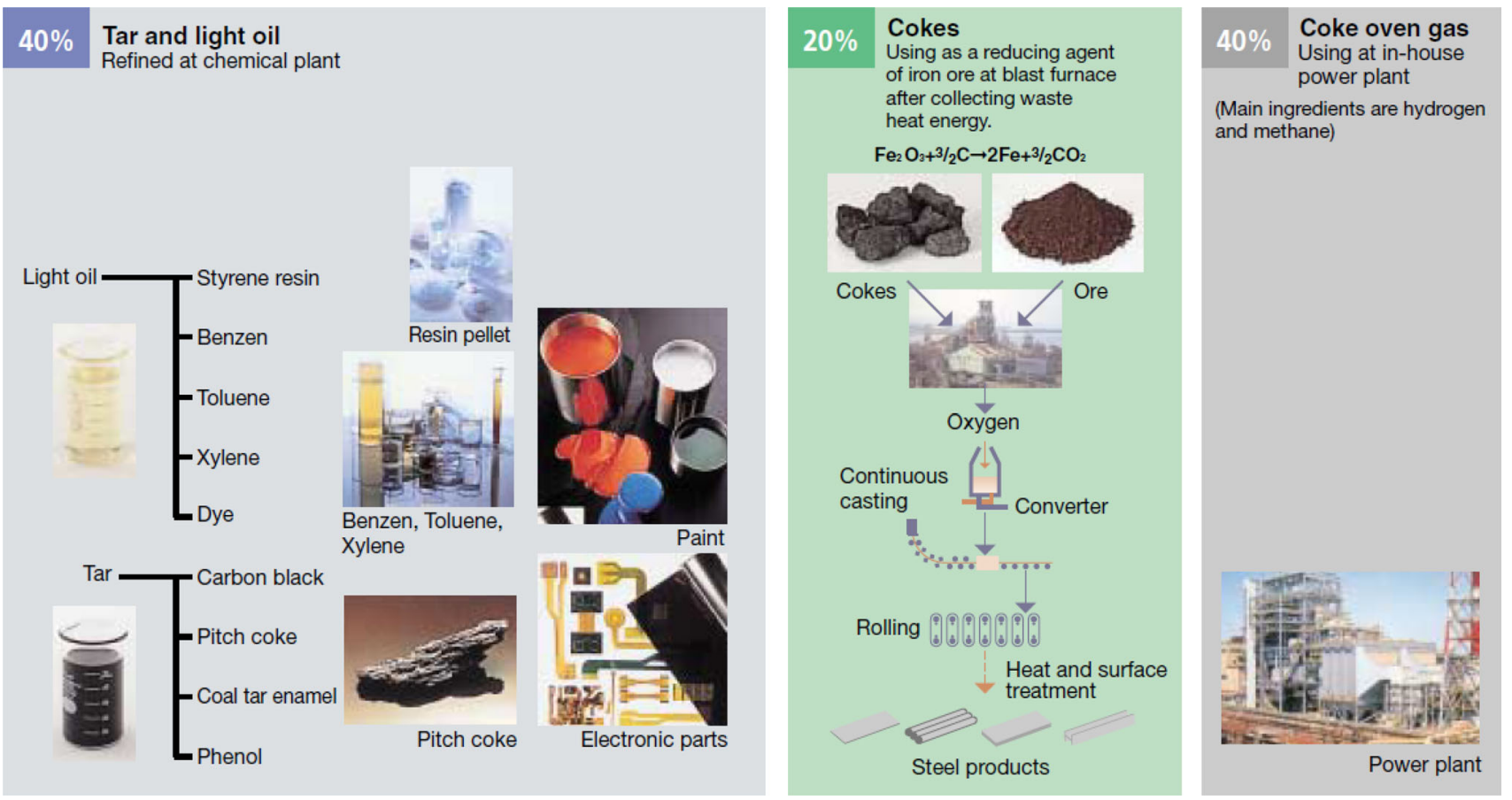

Fig. 17 Example of utilization for re-commercialization [8]

The first commercial-scale waste plastic-recycling plants were built at NSSMC Nagoya and Kimitsu works in 2000 . The treatment capacity was 40,000 t/year each. Since then waste plastic-recycling processes using coke ovens have been operating very smoothly, and most of the NSSMC steel works are equipped with the waste plasticrecycling process. Now roughly 200,000 tons per year of waste plastics are processed in coke oven under the container- and packaging-recycling system in Japan.

Future research topics for the use of waste plastics in coke oven are treating waste plastics other than household waste plastics and increasing the waste plastics addition rate. Waste plastics contain wide variety of plastic. Therefore, more precise studies on the relationship between plastic type and carbonization phenomena are necessary. The upper limit of waste plastic addition is determined by coke strength. It is known that in some cases, the addition of plastics could increase coke strength [9]. It could be possible to choose suitable industrial waste plastics and add these plastics by more than 1.5 mass $\%$ in coke ovens. Higher-density plastic agglomerates and separate charges of waste plastics [21] are to be investigated further for increasing the waste plastics addition rate.

\section{Conclusions}

To help in establishing a recycling-oriented society, NSSMC developed a waste plastic-recycling process using a coke oven and put it into commercial operation in 2000 for the first time in the world. Waste plastic containers and packaging from households are collected by municipal authorities. They are crushed and agglomerated to the sizes ranging from 20 to $30 \mathrm{~mm}$ in diameter at pretreatment facilities in our steel works. After being added to coal at the blending ratio of about 1 mass $\%$, waste plastic agglomerates are charged into coke ovens and thermally decomposed into approximately 20 mass $\%$ coke, 40 mass $\%$ hydrocarbon oil (tar and light oil) and 40 mass $\%$ COG. The coke is utilized as iron ore-reducing agent in blast furnaces, hydrocarbon oil as raw materials for the chemical industry and the gas as a fuel for power plants. Chlorine in waste plastics does not affect the chlorine content in coke and COG. Moreover, 92 mass\% of the chlorine in waste plastics is released and absorbed by the ammonia liquor spray for cooling hot COG and converted to ammonium chloride, while only 56 mass $\%$ of the chlorine in coal is released and absorbed. The waste plasticrecycling process using coke ovens is a high-performance, holistic in that a large amount of waste plastic can be treated, useful materials can be recovered using existing facilities, coke quality can be kept the same and the chlorine released from waste plastics can be fixed in the existing ammonia liquor spray system. We believe that this technology will make further contribution to the development of a sustainable social system and that we will continue to improve the process further.

\section{References}

1. Plastic waste management institute (2013) An introduction to plastic recycling. Plastic Waste Management Institute, Tokyo 
2. Plastic Waste Management Institute (2014) Plastic products, plastic waste and resource recovery 2012. PWMI Newslett 43

3. Asanuma M, Ariyama T, Sato M, Murai R, Nonaka T, Okochi T, Tsukiji H, Nemoto K (2000) Development of waste plastic injection process in blast furnace. ISIJ Int 40:244-251

4. Asanuma M, Kajioka M, Kuwabara M, Fukumoto Y, Terada K (2009) Establishment of advanced recycling technology for waste plastics in blast furnace. JFE Tech Rep 13:34-40

5. Janz J, Weiss W (1996) Injection of waste plastics into the blast furnace of Stahlwerke Bremen. 3rd Int Cokemaking Congress. CRM-VDEh, Gent, Belgium, 114-119

6. Kato K, Nomura S, Uematsu H (2002) Development of waste plastics recycling process using coke oven. ISIJ Int 42:S10-S13

7. Kato K, Nomura S, Fukuda K, Uematsu H, Kondoh H (2006) Development of waste plastics recycling process using coke oven. Nippon Steel Tech Rep 94:75-79

8. Nippon Steel Corporation Environmental Affairs Division (2002) Nippon Steel Environmental Report 2002. Nippon Steel Corporation, Tokyo, pp 16-17

9. Nomura S, Kato K, Nakagawa T, Komaki I (2003) The effect of plastic addition on coal caking properties during carbonization. Fuel 82:1775-1782

10. Díez MA, Álvarez R, Gayo F, Barriocanal C, Moinelo SR (2002) Study of the composition of tars produced from blends of coal and polyethylene wastes using high-performance liquid chromatography. J Chromatogr A 945:161-172

11. Domínguez A, Blanco CG, Barriocanal C, Alvarez R, Díez MA (2001) Gas chromatographic study of the volatile products from co-pyrolysis of coal and polyethylene wastes. J Chromatogr A 918:135-144

12. Amamoto K, Uemura N (1994) Influence of internal pressure during carbonization on coke quality and some means for the control. Curr Adv Mater Processes 7:944-947

13. Borozowska T, Zielinski J, Machnikowski J (1998) Effect of polymeric additives to coal tar pitch on carbonization behaviour and optical texture of resultant cokes. J Anal Appl Pyrolysis 48:45-58

14. Castro Diaz M, Edecki L, Steel KM, Patrick JW, Snape CE (2008) Determination of the effect caused by different polymers on coal fluidity during carbonization using high-temperature ${ }^{1} \mathrm{H}$ NMR and rheometry. Energy Fuels 22:471-479

15. Diez MA, Barriocanal C, Alvarez R (2005) Plastics wastes a modifiers of the thermoplasticity of coal. Energy Fuels 19: 2304-2316

16. Diez MA, Alvarez R, Melendi S, Barriocanal C (2009) Feedstock recycling of plastic wastes/oil mixtures in cokemaking. Fuel 88:1937-1944
17. Krishnan SH, Sharma R, Dash PS, Haldar SK, Biswas B (2006) Use of waste plastics in cokemaking at Tata steel. Ironmak Steelmak 33:288-292

18. Melendi S, Diez MA, Alvarez R, Barriocanal C (2011) Relevance of the composition of municipal plastic wastes for metallurgical coke production. Fuel 90:1431-1438

19. Melendi S, Diez MA, Alvarez R, Barriocanal C (2011) Plastic wastes, lube oils and carbochemical products as secondary feedstocks for blast-furnace coke production. Fuel Process Technol 92:471-478

20. Min Z, Cai-hong L, Lei M, Xiao-mei W, Zhi-lei Z (2009) Estimate research on co-carbonization of blend coal with waste plastics. Procedia Earth Planet Sci 1:807-813

21. Nomura S, Kato K (2005) Basic study on separate charge of coal and waste plastics in coke oven chamber. Fuel 84:429-434

22. Nomura S, Kato K (2006) The effect of plastic size on coke quality and coking pressure in the co-carbonization of coal/plastic in coke oven. Fuel 85:47-56

23. Sakurovs R (2003) Interactions between coking coals and plastics during co-pyrolysis. Fuel 82:1911-1916

24. Uzumkesici ES, Casal-Banciella MD, McRae D, Snape CE, Taylor D (1999) Co-processing of single plastic waste streams in low temperature carbonization. Fuel 78:1697-1702

25. Vivero L, Barriocanal C, Alvarez R, Diez MA (2005) Effect of plastic wastes on coal pyrolysis behaviour and the structure of semicokes. J Anal Appl Pyrolysis 74:327-336

26. Nomura S, Arima T, Kato K (2004) Coal blending theory for dry coal charging process. Fuel 83:1771-1776

27. Daybell GN, Pringle WJS (1958) The mode of occurrence of chlorine in coal. Fuel 37:283-292

28. Edgecombe LJ (1956) State of combination of chlorine in coal I: extraction of coal with water. Fuel 35:38-48

29. Fynes G, Herod AA, Hodges NJ, Stokes BJ, Ladner WR (1988) The thermal emission of chlorine-containing compounds from coal following brine and chlorine gas treatments. Fuel 67: $822-829$

30. Herod AA, Hodges NJ, Pritchard E, Smith CA (1983) Mass spectrometric study of the release of HCL and other volatiles from coals during mild heat treatment. Fuel 62:1331-1336

31. Nomura S (2014) Behavior of chlorine during co-carbonization of coal and chloride compounds in cokemaking process. Int J Coal Geol 130:27-32

32. Nomura S (2010) Behavior of coal chlorine in cokemaking process. Int J Coal Geol 83:423-429 